\title{
The Countermeasures of the Sustainable Development of Historical Sites Tourism Resources of Sima Qian and the Historical Records in Qin Dong Area
}

\author{
Liang Hongxian
}

School of Marxism, Weinan Normal University, Weinan, Shaanxi, 714099, China

Keywords: Qin Dong, Sima Qian, Historical Records, Historical Sites, Tourism Resources, Sustainable Development, Countermeasures

\begin{abstract}
Historical Records, written by Sima Qian, is a history work, covering a large number of Chinese tourism cultural resources and historical sites. The paper follows the text in the book to explore the rich historical relics, the "historical records" in the East Qin historical monuments and related tourism resources to integrate development, utilization and protection, analyzes the formation of rich charm and unique historical and cultural tourism resources, highlights the cultural quality, the advantages of historic cultural resources in the cultural industry, explores the effective countermeasures of sustainable development. It is of great practical significance to enhance the cultural transmission force and influence of Sima Qian and Shiji, and promote the economic and social development in eastern Qinling and the prosperity and progress of cultural tourism.
\end{abstract}

\section{Introduction}

"Historical records" is a shining star in the long history of the development of our country, have a profound influence on the development of our society, the "historical records", people know Sima Qian, a taste of its writing, firm and indomitable personality charm. Sima Qian is the Qin Qin East, East is located in the eastern part of Shaanxi Province, is the birthplace of our Chinese culture, the cultural tourism resources are rich, profound culture, carrying the historian Sima Qian the immortal spirit of dedication, inheriting the traditional culture of the Chinese nation outstanding, had a profound impact, there is good value for tourism development [1]. Therefore, how to integrate the development of Qin Dong Sima Qian and the "historical records" of the historic cultural tourism resources, carry forward the "historical records" culture, its unique charm, to cultivate the culture of self-confidence, promote the development and utilization of historical relics in Qindong area and sustainable development, has important practical significance.

\section{Historical Monuments and Cultural Resources in the Hometown of Sima Qian in the East of Qin Dynasty}

Qindong area including Linwei, Huayin, Weinan City, Hancheng district and two county-level cities, as well as Pucheng, Fuping, Tongguan, Dali, Huaxian, Chengcheng, water, Heyang and other 8 counties. The West connects with the provincial capital Xi'an, the border between South and Shangluo, north to Yanan and Tongchuan, and east to Shanxi and Henan two provinces, which is the east gate of Guanzhong Plain in Shaanxi province. Known as the source of the Chinese culture and the source of culture, the Qin Dong area has a long history and profound cultural background. Among them, Sima Qian and the historical tourism resources of historical records occupy an important position and become an important historical and cultural resource in the region. The history of the "hometown of Sima" is located in the Western Han Dynasty left Yixia Feng Yang, now Shaanxi city in Hancheng Province, is the famous hometown of Sima Qian, it contains rich tourism resources and a large number of original historical monuments, but also carries the profound connotation of Chinese culture, which contains a large number of Sima Qian related folk legends, ancient inscriptions, historical stories, historical monuments and so on [2]. The development and integration of related historical sites and cultural values can better bring their economic and social benefits into full play and promote the overall development of the regional 
economic and cultural culture in the east of the Qin Dynasty.

Sima Qian Cimu - Taishi temple is located in Hancheng City, Southeast of the town of shibakawa Gaogang, built in the Jin Dynasty Yongjia four years (310 years), the Taishi Temple retains a lot about the life of Sima Qian, the inscription records the "stay upright, upright fearless; sadness to become history, clears the antithetical couplet Sima Qian shows, upright and outspoken quality; otherwise February $1958 \mathrm{Mr}$. Guo Moruo wrote an inscription to the tomb of Sima Qian:" Longmen scenery, bell Yuren liuzhou, Xuezhi unprecedented rich, the unrivalled male. Exhale and Ying suddenly have sympathy for talented persons. After the father, exploits, Chiaki Taishi ", showing contemporary scholars on Sima Qian talent and knowledge of praise. The "Hancheng gazetteer" North "Huachi" section reads: "the legend of Si Maqian father Sima had a talk in the college teaching building in huachi." What is said is Sima Qian's book, "Sima academy", and the historic sites here show Sima Qian's precious qualities such as diligence and diligence [3]. There are some "Taishi race" and "Gong Temple", "run counter play", "February eight Sima Qian Temple Temple" to commemorate Sima Qian's custom, and "Liyudiaolongmen Legends" and so on, are the descendants of Sima Qian noble character thoughts and inheritance.

In the East Qin historical and cultural city of Hancheng, the "historical records" of historic cultural tourism resources including Yu temple in Hancheng City, 3 kilometers northeast of the week is the former, the temple of the earliest and most complete preservation of the temple, is a national key cultural relics protection units; also includes Wei Dongxiang Bao An Cun Dong has "San Yi tomb", is said to be the "historical records" in the "orphan" in the story, Cheng Ying, Wu Zhao gongsunchujiu cemetery. For these precious historical sites, in the rational exploitation and utilization, we should keep a large number of original ecological historic sites as far as possible. To improve its structure by increasing the number of ancient buildings associated with it and at the same time to add some text introduction, introduces the history of Sima Qian's life story and the "historical records" in the background, let visitors can enjoy the behind the deep historical and cultural connotation in the tour historical sites at the same time, realize the broad and profound Chinese nation the traditional culture [4]. In the sight-seeing, we get the edification of good feelings, enhance cultural confidence and sense experience, highlight the cultural value of tourist sites in historic sites, and promote the sustainable development of Sima's former residence, historic sites, tourist and cultural resources.

\section{Cultural Resources of Historical Relics Related to the Records of Historical Records in the East of Qin Dynasty}

In the "historical records", Sima Qian recorded from the legendary Huang Di to the emperor during next 3000 years of history, in the process of the war and the event records also recorded many historic relics and cultural tourism resources, from which we can feel the China natural scenery unlimited beautiful, also can realize the behind these historical sites associated with the history of the story reflected in the profound philosophy and wisdom of life is a generation of national heritage and look up later. Zhang Liangyun: "the husband left in Yao letter, right Gansu and Sichuan, vast. This is also called the land of abundance well-guarded." Guanzhong is located in the western part of Tongguan, Shaanxi, to the east of Baoji, which is the five prefecture level cities in Xi'an, Tongchuan, Baoji, Xianyang and Weinan, which are overlapped and closely related to today's eastern Qinling area [5]. Sima Qian had a deep feeling for the land that raised his own growth. "Historical records" in the Guanzhong and Qindong cultures and customs records, and Sima Qian and the "historical records" relevant historical historic relics, still nourish life in this fertile land of the people, the descendants of fukuzawa.

In the vast land of the east of Qin Dynasty, the historical relics related to the historical records are very rich. Because in the vicinity of the Qin Empire capital, the "historical records" of Qin history records more, such as "Qin Ji", "Qin Shihuang Ji", "Assassin biography", "Shangjunshu biography", "Lv Buwei biographies" Wang Jian's biography "," white, "biographies of Lian Po Lin Xiangru" "Meng Tian's biography", etc. the main historical monuments, resources including Fuping Xian Zhen Wang Jian tomb, Dali Wei the Great Wall, Chengcheng County Liang Zhou site and so 
on, after washing through history, is still in its own cultural relics to be silent recounting the history of that year. Sima Qian as a famous historian in Western Han Dynasty, also made a record of the history of Han Dynasty before the Western Han Dynasty, its main contents are "Ji", "emperor Lu Ji", "Ji", "emperor Hsiao Wu Ji", "Xiang Yu Ji", "Cao Xiangguo," Xiao Xiang family "in the family", "Liu Hou family", "Huaiyin Hou," biography "," Wei "biographies of cruel officials of the Wuan Hou biography", corresponding to the Qin East District of Lintong including places of historic interest and scenic beauty feast sites, Heyang Xia Yang ferries, the warehouse sites etc.. Hongmenyan tells the story and at the same time the historical stories; Xia Yang Du Heyang recorded at the time of the Han Huaiyin Hou Han from here with a wooden vase in the crossing, and the capital of Huayin Weidu; warehouse sites built in Han Dynasty, Changan is the capital of the state of grain storage and transport of large granary [6]. These historical monuments and cultural resources is also a valuable spiritual wealth for future generations, so the development of historical relics and the development of its hidden behind the spiritual wealth of the spiritual and material culture are interdependent and complement each other, in order to make the Qin Dongdi District historic tourist resources development showing the momentum of sustainable development.

\section{Developing the Cultural Resources of Historical Monuments of Sima Qian and Historical Records and Carrying Forward the Excellent Traditional Culture of China}

"Jue six different CO, neat 100 Miscellaneous language" of the "historical records" in pre Qin and Han culture of the great, then almost all of the Chinese include historical stories and cultural allusions, is a rich historical encyclopedia, in the study of "historical records" records, must not only put in the eye the research and development of the written history of cultural heritage resources, and ignore the history behind the story, this is also an important part of the historical and cultural resources. Through viewing on the tour of Sima Qian and the "historical records" historical monuments, historical monuments in the visitors browsing laments the great magic at the same time, can stimulate their love for the motherland and the beautiful rivers and mountains of a country more tourists, patriotism, and understanding of the excellent national culture spirit of this historical monuments contains the historical stories and show the Sima Qian and the "historical records" is the historical and cultural monuments has great value for development, but should be rational development rather than blindly or excessive development, should be combined with the development and protection, at the same time to retain a large number of original historical monuments, built some ancient buildings to improve building structure [7]. Appropriate to add some text, such as the historical background of Sima Qian's life, and the "historical records" related were introduced, allowing visitors to visit historical places at the same time can understand the history behind the story, to feel the broad and profound Chinese traditional culture, have better emotional edification in the mind, enhance cultural self-confidence and sensory experience tourism thus, the historic resort tourism cultural value can be truly reflected.

\section{The Countermeasures of the Sustainable Development of the Historical Relics of the Historical Sites of Sima Qian and the Historical Records of the Qin Dynasty}

Mr. Zhang Xinke in his writing "historical studies" in the sermon: "Sima Qian and the" historical records "is a very cultural connotation of the brand, made the cultural brand, can serve the modern society, have certain economic benefits." Reasonable development and integration of Sima Qian and the historical records of the historical sites tourism cultural resources, to achieve sustainable development, the following are the following aspects:

\subsection{Dig up cultural resources, build and repair historical and cultural relics related to Sima Qian and historical records in the east of Qin Dynasty}

Qin Dong Sima Qian and the "historical records" of the causes and effects of some places of historic interest and scenic beauty, the natural environment of the time, appear different degree damage surface or structure; some precious historical relics due to long-term protection and repair 
improper, wind and rain erosion or different periods in history of people, the integrity of the damaged or even face has disappeared, resulting in the loss and waste of historic cultural resources. For historic sites that have been discovered but damaged by function, we should use professional technical means to carry out remedial measures, and clean up the historical sites that have been completely scrapped after failure [8]. To the relevant historical records review story "historical records" and the corresponding historical monuments, located in search of historical monuments, and according to the modern technology to carry out the protection and rebuilding of historical monuments, explore the history behind the story, the successful development of tourism and cultural historical monuments can achieve its cultural value. An example of developing such as Zheng Huan Huaxian cemetery is worthy of reference.

In the repair of Qin Dong Sima Qian and the "historical records" historical sites at the same time, also can be in Sima Qian or "historical records" in the historical figures in Qindong activities to build some of the monuments, supplemented by text introduction, to enhance Qin Dong Sima Qian and the "historical records" historical resources and cultural heritage and cultural atmosphere. Established in recent years by Sima Qian Cimu as the core of the "historical records of the museum" and "historical city", tourism, catering, leisure and shopping, can effectively promote the development and utilization of East Qin historical monuments of cultural tourism resources and sustainable development.

\subsection{Relying on the Hancheng City, the radiation around the surrounding, the development and addition of Sima Qian and the "historical records" related historical tourism content or project}

In addition to building or restoring Sima Qian and the commemorative buildings related to Shiji, we should also develop or expand the contents and projects of the historic sites in the east of the Qin Dynasty. By launching the one-day or half day tour of historical figures or historical sites in historical records, we will increase and enrich the cultural connotations of historic sites and attract more tourists to visit. Considering every year in Hancheng in recent years to come to watch the tour a lot of people, can open up Sima's hometown Tourist Bus Line, the circuit design into a stretched version of line link the various attractions to the surrounding area, dispersed flow, both to prevent tourists from Hancheng sites and services center caused by traffic pressure, but also realize the unique building in Hancheng theme tourism area of vision, but also to promote the development of the surrounding counties economy [9]. In addition, after textual research in Hancheng and its surrounding counties, some living places of Sima Qian's life can be built. The historical figures related to the activities of the East Qin's "historical records" in the can in related sites for the statue and monument carved Sima Qian and the "historical records" of the famous aphorism, "Shihchi Taishigong preface" tree stele carving, make it become the city of Hancheng and East Qin rich the iconic attractions.

\subsection{Carrying out various forms of cultural and creative activities and Sima's cultural and recreational activities}

The construction of cultural and creative industry cluster must start from the actual situation in the eastern part of Qin Dynasty, mainly from the aspects of cultural facilities construction, cultural heritage preservation, cultural personnel training and other aspects, to build integrated service system of tourism culture in historic sites in East Qinling. Such as the establishment of special historical museum, city and county in Qin East Museum, showcasing local cultural content, open the corresponding cultural village, cultural corridor, cultural workshops and other cultural products to achieve display, technology demonstration, television broadcasting style; or thematic exhibition, theme park, leisure and entertainment use of historical monuments, historical scene folk culture experience form East Qin cultural resources, to create Sima Qian and the "historical records" cultural creative industry cluster. We can draw lessons from the experience of developing Confucius tourism in Qufu, Shandong, and draw lessons from the development of the cultural tourism of the Qin East Sima Qian. Through creative culture activities, we can deepen our understanding of Sima Qian and Shiji's cultural resources in historical sites, and promote the sustainable development of 
East Qinling's economic culture. At the same time, can also rely on Sima Qian and the "historical records" rich historical and cultural knowledge, to carry out various forms of knowledge and history knowledge contest held fun quiz, large-scale theatrical performances, as well as related entertainment and cultural activities and so on, let visitors in a relaxed and pleasant atmosphere, feel the history of the broad and profound understanding of history.

\subsection{Developing cultural tourism products related to Sima Qian and "historical records"}

To explore the development of ideas, not only to the development and production of some distinctive Qindong area of Sima Qian and the "historical records" of the ordinary tourist souvenirs, such as handkerchief, tablecloth, cultural shirt, "the famous sculpture crafts, bookmarks, badges and other kinds of small handicrafts, can also develop some of Qin Dong Sima Qian and the" historical records "historical monuments, historical figures, historical stories of a grade, the collection value and with the local characteristics of fine tourism commodities, such as the Sima Qian and the" historical records "of the CDs, books, historical stories, painting calligraphy, jewelry miniature word aphorism, the historical figures of Qin East unique paper cutting, shadow etc. reproduction of" historical records "in the story. The combination of cultural investigation, historical sites, sightseeing, sightseeing, shopping and catering culture can play a role in publicizing Sima Qian spirit and the culture of Shiji, so as to realize the sustainable development of tourism resources of historic sites in Sima Qian and Shiji.

\section{Acknowledgements}

This paper would thank to the fund project: 2015 annual Weinan Normal University humanities and Social Sciences talent fund project: an investigation on Development of Historical and Cultural Heritage Resources of Sima Qian and Historical Records in Qin Dong(15SKRC04); scientific research projects in 2017 (Humanities and Social Sciences): Difficulties and Countermeasures of Transformation of Qindong Cultural Resources to Cultural Industry (17HX86).

\section{References}

[1] Chen T T. Countermeasures and Evaluation of the Sustainable Development of Coastal and Marine Tourism in Shandong Province[J]. Journal of Binzhou University, 2010, 2(3):169-76.

[2] Tian X X, Liu J M, Yan M. SWOT Analysis and Countermeasures Research on the Development of Turpan Sand-Therapy Tourism Resources[J]. Advanced Materials Research, 2013, 734-737:3295-3301.

[3] Wu W, Wang H, Li X. Route and countermeasures for the establishment of ecological cultural tourism environment[C]// Second International Conference on Mechanic Automation and Control Engineering. IEEE, 2011:3415-3417.

[4] Yan Z, Mao L, Luo W. Environmental problems in tourism resources development and countermeasures: Zhangye Danxia National Geological Park in Gansu Province as an example[C]// International Conference on Earth Science and Environmental Protection. 2013:831-836.

[5] Zhang H Y. The Countermeasures Research on Xingtai Tourism Sustainable Development Based on SWOT Analysis[J]. Advanced Materials Research, 2012, 518-523:5882-5885.

[6] Li Y S. Development status and countermeasures of rural tourism resources in Qindong area. [J]. Guizhou Agricultural Sciences, 2012:214-216.

[7] Zhou G. On Henan's Development of Special Cultural Tourism by Exerting Its Advantages of Cultural Resources[M]// Advances in Education and Management. Springer Berlin Heidelberg, 2011:433-439.

[8] Zhao J, Wang Y. The Sustainable Development Research of Wild Plant Tourism Resources Based on the Entropy-AHP Evaluation Method[J]. Advance Journal of Food Science \& Technology, 
2016, 10(2):81-89.

[9] Mckinnon A D, Williams A, Young J, et al. Tropical marginal seas: priority regions for managing marine biodiversity and ecosystem function[J]. Annual Review of Marine Science, 2014, 6(6):415. 